\title{
The Amazon Rubber Boom, 1850-1920
}

Barbara Weinstein. This is a full-scale account of one of the most epic "boom and bust" cycles in Latin American history-the Amazon rubber trade's 7o-year dominance of the Brazilian economy. Broken by the successful cultivation of rubber trees by the British in Southeast Asia, the long period of vigorous economic activity in the rubber trade left the basic structure of Amazonian society relatively unchanged. One of the author's main concerns is to explore why rubber exports did not generate substantial growth in either the industrial or the agricultural sectors. She also considers the impact of political decentralization and regionalism on the economy, draws comparisons with the coffee boom in São Paulo, and traces the consequences of the rubber economy's collapse on the social, political, and economic life of the region. \$29.50

\section{Stanford University Press}

\section{THE ARTHUR H. COLE GRANTS-IN-AID}

\section{For Research in Economic History}

- are awarded each year to supplement other sources of research support;

- are biased in favor of young post-doctorates turning dissertations into publishable articles and monographs, but are open to all;

- are awarded by the six-member Committee on Research in Economic History on the basis of an application due on April 1 each year;

- are granted for research in any geographic region in the world and in any time period;

- are described in more detail in a prospectus sent out by the Secretary, Council on Research in Economic History. The Economic History Association, Box 3630, Wilmington, Delaware 19807. 


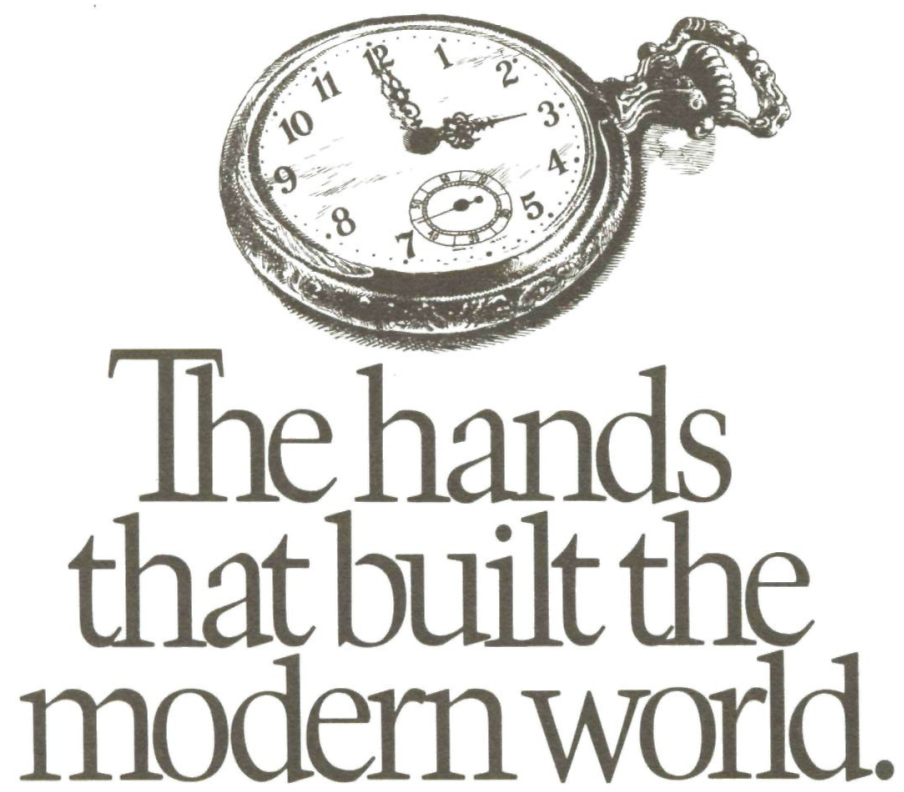

In the twelfth century, Europeans witnessed the birth of an invention that would change forever the way people lived, and set the stage for both the industrial revolution and the political and economic ascendancy of the West.

In an engaging chronicle that encompasses three continents and 1,000 years, master historian David Landes traces the lifespan of the mechanical clock.

The multiple themes of religion and culture, science and technology, economic history and politics, are skillfully combined to show how and

why this invention occurred in Northern Europe and remained a European monopoly for 500 years. Landes describes the evolution of timekeeping devices-from the waterclock of ancient China to modern precision watches. He also tells the story of the craftsmen who made clocks and watches, and how they made them.

"Truly dazzling. This is a distinguished work full of wisdom and insight. A landmark book"

- William H. McNeill, University of Chicago

With 8 color plates, $28 \mathrm{~b} / \mathrm{w}$ halftones, 13 line illustrations. $\$ 20.00$

\section{Revolution inTime}

Clocks and the Making of the Modern World

David S. Landes

The Belknap Press of

Harvard University Press

Cambridge,MA 02138 